\title{
DONACILLA CORNEA (POLI, 1791) (BIVALVIA: VENERIDA: MESODESMATIDAE) IN THE NORTHERN BLACK SEA: NEW DISTRIBUTION RECORDS, SHELL SIZE AND COLOURATION
}

\begin{abstract}
BORIS LINETSKII
Odessa I. I. Mechnikov National University, Shampanskii Ave, 2, 65082 Odessa, Ukraine (e-mail: linetskii.bg@gmail.com)

ABSTRACT: The first record of Donacilla cornea (Poli) from Ukrainian beaches since 1960 is presented. The populations from the northern Black Sea were studied for their size and colour polymorphism. The maximum shell length was $26.05 \mathrm{~mm}$, thus exceeding the previously reported values. The shell size differences between the populations and the similarity of shell shape indices were confirmed by one-way ANOVA. The negative allometry of height and width to length was confirmed by the t-test of linear regression slopes. Twelve patterns and seven background colours were recorded. Three patterns were observed for the first time. Significant differences in the frequency of colour pattern, and the similarity of pattern and shell colour between the studied populations were confirmed using Pearson's $\chi^{2}$. In the northern Black Sea populations white, non-streaked forms without radial pattern prevailed. The potential colour variation, estimated with ACE for each population, was close to the observed variation.
\end{abstract}

KEY WORDS: morphometry; colour polymorphism; shell pattern; swash zone

\section{INTRODUCTION}

Donacilla cornea (Poli, 1791) is a burrowing bivalve inhabiting medium- to coarse-grained sands and rocky shores. The species is distributed over the Azov, Black, and Mediterranean Seas, as well as the Atlantic coast of Europe (DUMONT et al. 1999). In the 20th century, D. cornea was widespread in Ukraine, recorded from Western Crimea, Danube-Dniester interfluve, Kinburn Spit, Tendrovsky Peninsula and Dzharylgach Island. Since the late 1960s, its habitats have sharply declined (ZAKUTSKY 1967). The decline was associated with eutrophication of the Black Sea, and now the species is regarded as threatened (EN) at the regional (Black Sea) level (DUMONT et al. 1999, MICU \& MICU 2006). In the last years, however, many Black Sea populations were rediscovered, because of the increasing population density (MICU \& MICU 2006, KOPII 2012, SON 2014). The absence of pelagic stage in the life cycle of $D$. cornea (BĂCESCU et al. 1967) may suggest that many of the modern populations are indeed survivors from the sharp density decline in the late 1960s. The fragmentation of the species' habitats is too great to suppose the possibility of distant along-shore migrations.

MICU \& MiCU (2006) observed depth segregation in the Romanian Black Sea, but there were no data from other populations so that the phenomenon could not be regarded as a general rule. The presence of relatively big shells can reflect both a high longevity and a fast growth of the bivalves. The extremely high maximal shell length may indicate a good population condition and stability of environmental conditions (MICU \& MICU 2006).

The shell colour and pattern of D. cornea were described for the Mediterranean and Atlantic coasts (WHiteley et al. 1997). The aim of this study was to estimate and compare the shell size characteristics and colour polymorphism of the northern Black Sea populations of $D$. cornea which till now remained unstudied.

The shell length, height, width, and shape indices were compared for four northern Black Sea populations. The dependences between shell length and 
other measurements were studied. The frequencies of the variants of pattern, its colour, background colour, and the degree of periostracum expression, were compared among the studied populations and with literature data. The potential diversity of each colouration element was estimated.

\section{MATERIAL AND METHODS}

The specimens for this study were sampled from four sites (Fig. 1): 1) gravel spit of Lake Sasyk-Sivash in the vicinity of Evpatoria city (Crimean peninsula) (153 specimens) 19.05.2013; 2) southern shore of Dzharylgach Island (Kherson region) with medium-grained sand (40 specimens) 20.08.2016; 3) beach on Budakskaya Spit (Odessa region) with medium-grained sand (107 specimens) 23-25.08.2017; 4) shore between villages Grigorovka and Chabanka (Odessa region) with medium-grained sand (35 specimens) 22.08.2019. Each sample was randomly collected from the swash zone, manually and with a square sampling frame $\left(10 \mathrm{~cm}^{2}\right)$ to the depth of 20 $\mathrm{cm}$, and washed through a sieve of $2 \mathrm{~mm}$ mesh.

The Sasyk sample was stored in $96 \%$ ethanol solution. There were no changes in colour between sampling and colour estimation. Other specimens were measured and recorded during the sampling and released into the habitat. Shells were measured with an electronic calliper with $0.01 \mathrm{~mm}$ accuracy. Standard measurements of bivalve shells were taken: maximum length $(\mathrm{L})$, height $(\mathrm{H})$, and total width of two cusps (W). Their shape indices: W/L, H/L, and $\mathrm{W} / \mathrm{H}$ were calculated.

The Sasyk sample measurements had a bimodal distribution, so, for morphometric comparisons, it was divided in two groups (Sasyk-1 with 38 individuals and Sasyk-2 with 92) using maximum likelihood method. Only individuals which were assigned to one group by all three parameters were used in the analyses. All the samples conformed to the assumptions of normal distribution (Shapiro-Wilk's W test,

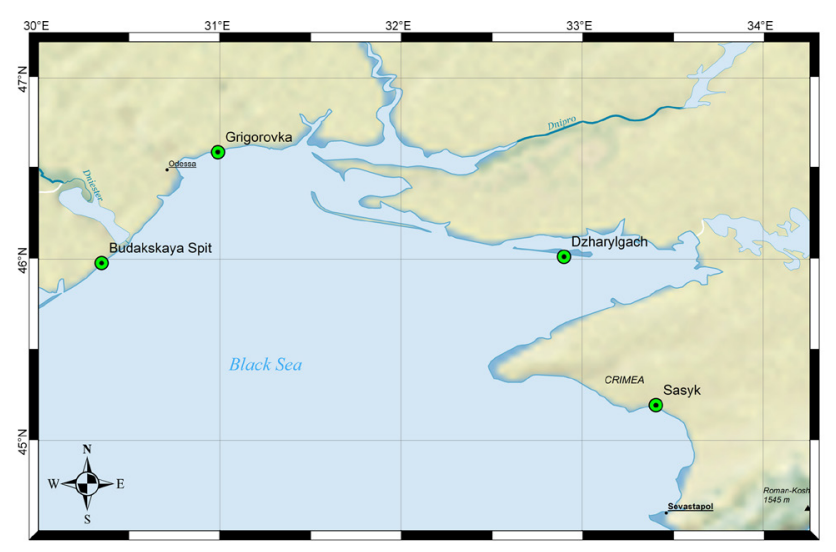

Fig. 1. Map of the study sites
The information on the condition of the populations of $D$. cornea and the new records should aid a more precise estimation of its conservational status and planning of protection measures.

$\mathrm{p}>0.05)$ after the exclusion of outliers. Arithmetic mean with a $95 \%$ confidence interval, maximum and minimum of each measurement, and shape indices were calculated for each sample. One-way ANOVA was used for comparison of measurements. Because of significant heteroscedasticity (Levene's test, $\mathrm{p}<0.1$ ), Welch's F test was used. The Games-Howel post-hoc test was used to identify significant differences between the pairs of populations. All the samples except Grigorovka conformed to the assumptions of normal distribution and homoscedasticity of their shell shape indices (Shapiro-Wilk's W test, $p>0.05$; Levene's test, $p>0.05$ ) after the exclusion of outliers. One-way ANOVA was used to compare the populations. The shape indices of Grigorovka were excluded from the parametric analyses. The leastsquare linear regression was used to estimate the morphometric relationships between $\mathrm{L}$, as the independent variable, $\mathrm{W}$, and $\mathrm{H}$. All the pairs conformed to all assumptions associated with the linear regression model. The association degree was calculated by the determination coefficient $\left(\mathrm{r}^{2}\right)$. The equality of intercepts (a) and slopes (b) was assessed using ANCOVA. The one-sample t-test was used to check the hypothesis of isometric growth $\left(\mathrm{H}_{0}: \mathrm{b}=1\right)$ using the methodology described by GASPAR et al. (2002).

Four colouration elements were recorded for each individual: pattern, background colour, pattern colour, and degree of expression of periostracum. The shells were classified according to the pattern, as described by WHITELEY et al. (1997). The presence and degree of periostracum expression were assessed on an ordinal scale from complete absence, through low - yellow, mainly at the outer edge of the shell, to high - from yellow to brown, covering more than $75 \%$ of the shell surface. The similarity of frequencies of shell colouration variants was tested using Pearson's $\chi^{2}$, calculated based on the maximum likelihood method. Significance levels were estimated using the Monte Carlo algorithm $\left(\mathrm{P}_{\mathrm{MC}}\right)$. The potential diversity of colouration elements was estimated using the abundance-based coverage estimator - ACE (CHAO \& LEE 1992).

All statistical calculations were performed using the statistical software IBM SPSS, PAST, and SPADER (HAMMER et al. 2001, CHAO et al. 2015, IBM CORP. 2017). 


\section{RESULTS AND DISCUSSION}

\section{NEW DISTRIBUTION RECORDS}

This is the first record of $D$. cornea on the Grigorovka beach and the first post-1960 record from the Budakskaya Spit. These records and the other findings suggest that the populations of $D$. cornea of the northern Black Sea are now recovering (MICU \& MiCU 2006, KOPII 2012, SON 2014). However, there is no firm evidence to support either the bottleneck or the founder effect hypothesis. The search for $D$. cornea is complicated because of its low population density, as well as vertical and across-shore migration activity.

\section{SHELL SIZE AND SHAPE INDICES}

The main characteristics of shell size and shape are presented in Table 1 . The mean length of $D$. cornea in the Romanian population in the swash zone is $10.62 \mathrm{~mm}$, and the maximum is $24.00 \mathrm{~mm}$ (MICU \& MICU 2006). The maximum length in the Romanian population, predicted by MICU \& MICU (2006) using Von Bertalanffy's growth function, was 24.23 $\mathrm{mm}$, and greater values were observed only in the Mediterranean Sea (up to $25.00 \mathrm{~mm}$ ). The maximum length of $D$. cornea from the Dzharylgach and Budakskaya populations significantly exceeded these values (Table 1).
The absence of small clams in the swash zone confirms the depth segregation phenomenon, previously observed in the Romanian population of $D$. cornea (MICU \& MICU 2006): bigger individuals prefer deeper zones. However, across-shore migrations can change this pattern, as it was observed in the Sasyk population, where the distribution of measurements was bimodal - two size classes occupied the same zone. Thus, the obtained values of the main shell parameters only represent size classes in the swash zone in a certain period. On the studied sandy beaches, D. cornea was not found on the other across-shore levels up to the $20 \mathrm{~cm}$ depth; estimation of its spatial structure needs a more detailed study.

The presence of old, big individuals in the Dzharylgach and Budakskaya populations can serve as an indicator of the high stability of these populations. However, the data on Sasyk and Grigorovka are not sufficient to provide an unequivocal estimation.

The studied populations show significant differences for all three size characteristics (Table 2). Games-Howell post-hoc test confirmed significant differences between populations in all pairs $(\mathrm{P}<0.001)$. The interpopulation differences between the mean shape indices were not significant (Table 3 ).

The $\mathrm{r}^{2}$ confirmed good correlation of shell size parameters in both linear models (Table 4). The

Table 1. Means with 95\% confidence intervals, and ranges of shell measurements and shape indices

\begin{tabular}{lcccc}
\hline \multirow{2}{*}{$\begin{array}{c}\text { Measurements and } \\
\text { shape indices }\end{array}$} & \multicolumn{4}{c}{ Population } \\
\cline { 2 - 5 } L, mm & Dzharylgach & Sasyk & Budakskaya & Grigorovka \\
& $23.17 \pm 0.45$ & $18.91 \pm 0.27$ & $20.33 \pm 0.54$ & $11.10 \pm 0.62$ \\
& $16.98-25.64$ & $14.32 \pm 0.26$ & $11.88-26.05$ & $6.27-14.71$ \\
W, mm & & $9.81-20.70$ & & $3.23 \pm 0.21$ \\
& $7.53 \pm 0.20$ & $6.54 \pm 0.15$ & $6.68 \pm 0.25$ & $1.84-4.56$ \\
H, mm & $4.69-9.25$ & $4.51 \pm 0.08$ & $3.41-9.81$ & $6.66 \pm 0.40$ \\
& & $3.52-7.30$ & & $3.95-9.00$ \\
W/L & $14.10 \pm 0.25$ & $11.77 \pm 0.21$ & $12.46 \pm 0.37$ & \\
& $9.61-17.44$ & $8.70 \pm 0.15$ & $6.69-16.37$ & $0.289 \pm 0.002$ \\
H/L & & $6.49-13.02$ & & $0.267-0.322$ \\
& $0.325 \pm 0.003$ & $0.326 \pm 0.002$ & $0.330 \pm 0.003$ & $0.599 \pm 0.003$ \\
W/H & $0.276-0.364$ & $0.275-0.420$ & $0.276-0.430$ & $0.557-0.634$ \\
& $0.609 \pm 0.003$ & $0.615 \pm 0.002$ & $0.613 \pm 0.002$ & $0,484 \pm 0.003$ \\
\hline
\end{tabular}

${ }^{*}$ Means and CIs given for Sasyk-1 and Sasyk-2 measurements separately

Table 2. One-way ANOVA of shell size parameters

\begin{tabular}{lcccc}
\hline & Welch's F & df & P & $\eta^{2}$ \\
\hline $\mathrm{L}$ & 441.692 & 4 & $<0.001$ & 0.791 \\
$\mathrm{~W}$ & 385.953 & 4 & $<0.001$ & 0.715 \\
$\mathrm{H}$ & 490.377 & 4 & $<0.001$ & 0.763 \\
\hline
\end{tabular}

Table 3. One-way ANOVA of shell shape indices

\begin{tabular}{lccc}
\hline & F & Df & P \\
\hline W/L & 0.780 & 2 & 0.459 \\
$\mathrm{H} / \mathrm{L}$ & 1.815 & 2 & 0.165 \\
$\mathrm{~W} / \mathrm{H}$ & 2.232 & 2 & 0.109 \\
\hline
\end{tabular}


Table 4. Linear regression parameters of shell length vs. width and height models, and results of t-tests on isometric shell growth

\begin{tabular}{clcccccc}
\hline Model & Population & $\mathrm{r}^{2 *}$ & Intercept & SE & Slope & SE & t-test $^{*}$ \\
\hline L-W & Budakskaya & 0.865 & -1.366 & 0.316 & 0.399 & 0.016 & -38.60 \\
& Dzharylgach & 0.695 & -0.939 & 0.925 & 0.364 & 0.040 & -15.82 \\
& Sasyk & 0.871 & -0.852 & 0.197 & 0.381 & 0.012 & -49.80 \\
& Grigorovka & 0.957 & -0.282 & 0.132 & 0.316 & 0.012 & -57.89 \\
L-H & Budakskaya & 0.947 & -1.060 & 0.318 & 0.667 & 0.016 & -21.28 \\
& Dzharylgach & 0.815 & 0.262 & 1.087 & 0.595 & 0.047 & -8.57 \\
& Sasyk & 0.940 & -0.302 & 0.216 & 0.634 & 0.014 & -26.90 \\
& Grigorovka & 0.972 & -0.233 & 0.208 & 0.620 & 0.019 & -20.43 \\
\hline
\end{tabular}

${ }^{*}$ In each case $\mathrm{p}<0.001$.

ANCOVA confirmed significant differences in the values of intercept $(\mathrm{p}<0.001)$ and similarity of slopes $(p>0.1)$ in both cases. Thus, despite the differences in initial ratios, the proportions of shells in the studied populations undergo similar changes during the growth. The lower the intercept, the more elongated form the shell takes during the initial growth stages. The negative allometric growth pattern of $D$. cornea was confirmed by the t-test (Table 4): the shell length increases faster than the width and height. The negative allometry could be regarded as an adaptation to the burrowing lifestyle (GASPAR et al. 2002).

\section{COLOUR PATTERN}

Seven variants of the shell background colour were noted (Fig. 2). There were no significant differences in frequencies of these variants between samples $\left(\chi^{2}=17.10 ; \mathrm{df}=18 ; \mathrm{P}_{\mathrm{MC}}=0.556\right)$. In all the studied populations white shells prevailed (61-80\%), whereas in the Mediterranean and the Atlantic brown shells were most abundant (19-39\%) (WHITELEY et al. 1997).

Twelve variants of shell pattern were recorded (Fig. 3). Three of them had not been described by WHITELEY et al. (1997): $\mathrm{E}_{1}$ (type $\mathrm{E}$ with radial lines), $\mathrm{B}_{0 \mathrm{c},}$ and $\mathrm{B}_{1 \mathrm{c}}\left(\mathrm{B}_{0}\right.$ and $\mathrm{B}_{1}$ with bands, consisting of dense lines). Shells with patterns $B_{0 b}, B_{1 b}, C_{1}$, E, specified for

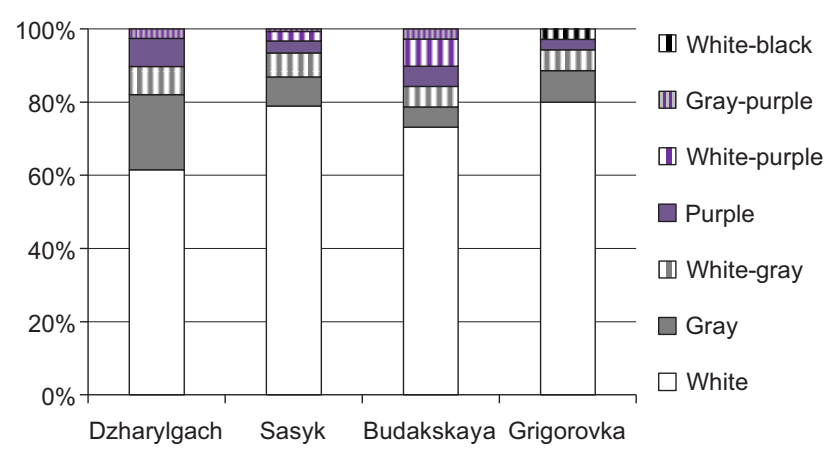

Fig. 2. Frequencies of shell background colour in four studied sites the Mediterranean and Atlantic coasts by WHITELEY et al. (1997), were absent in the studied populations. Only in the Grigorovka sample specimens with $\mathrm{E}_{1}$ pattern were found, and the radial lines were merged into zigzags, as in the Mediterranean Sea and the Atlantic Ocean (WHITELEY et al. 1997).

No significant differences in the pattern frequency were found between the studied populations $\left(\chi^{2}\right.$ $=51.03 ; \mathrm{df}=33 ; \mathrm{P}_{\mathrm{MC}}=0.016$ ) (Fig. 4). Unlike the Mediterranean and Atlantic populations, studied by WHITELEY et al. (1997), where B-variants were most abundant, on the northern Black Sea coast A-forms prevailed (66-75\%).

WHITELEY et al. (1997) pointed out that radial pattern elements were connected, suggesting linkage or epistasis might be involved in the phenotype inheritance. This is supported by the fact that only lines can be transparent and by the absence of streaked $\mathrm{F}$ and $\mathrm{G}$ forms. On the other hand, finding streaked E-forms indicates that this connection is not absolute. The question of the genetic architecture underlying the polymorphism in $D$. cornea requires a detailed study.

The frequencies of streaked patterns in the northern Black Sea were $20.5 \%$ for Dzharylgach, $19.7 \%$ for Sasyk, 30.5\% for Budakskaya spit, and $40.0 \%$ for Grigorovka. Compared to WHITELEY's et al. (1997) results, where frequencies of the streaked patterns were $42.9-57.7 \%$, in the studied populations nonstreaked patterns prevailed.

In general, there were significant differences in the frequency distribution of shell pattern colour between the studied samples $\left(\chi^{2}=72.63 ; \mathrm{df}=24 ; \mathrm{P}_{\mathrm{MC}}\right.$ $<0.001$; Fig. 5).

Highly significant differences were noted in frequencies of classes reflecting the expression of periostracum $\left(\chi^{2}=104.34 ; \mathrm{df}=6 ; \mathrm{P}_{\mathrm{MC}}<0.001\right)$. The shells without periostracum were most common. Only in Sasyk individuals with low periostracum expression prevailed (Fig. 6).

The estimated potential variation of colouration elements was close to the total observed except the Grigorovka population (Table 5). The estimated diversity of shell pattern colour in the Dzharylgach and 

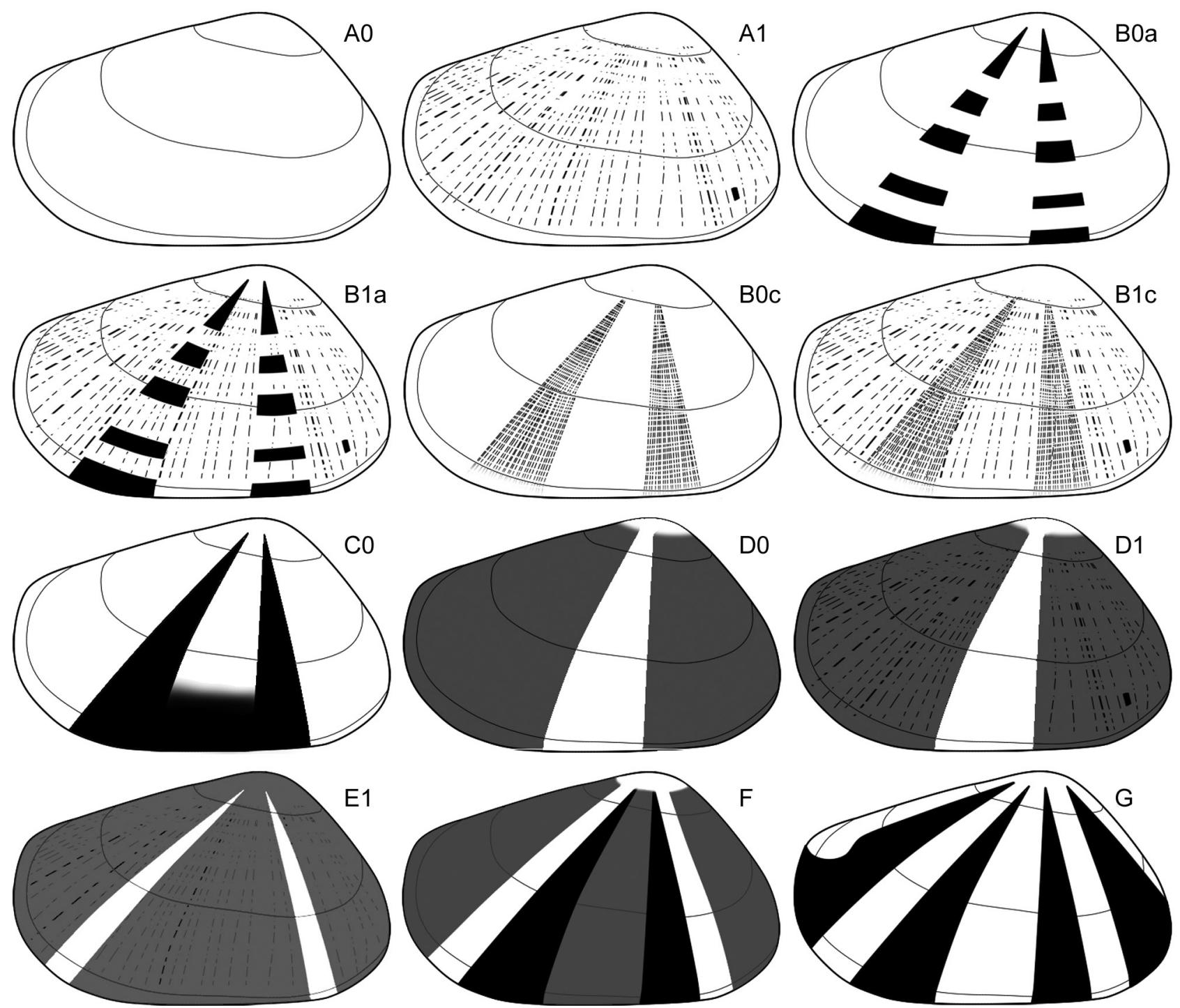

Fig. 3. Shell patterns from the studied samples
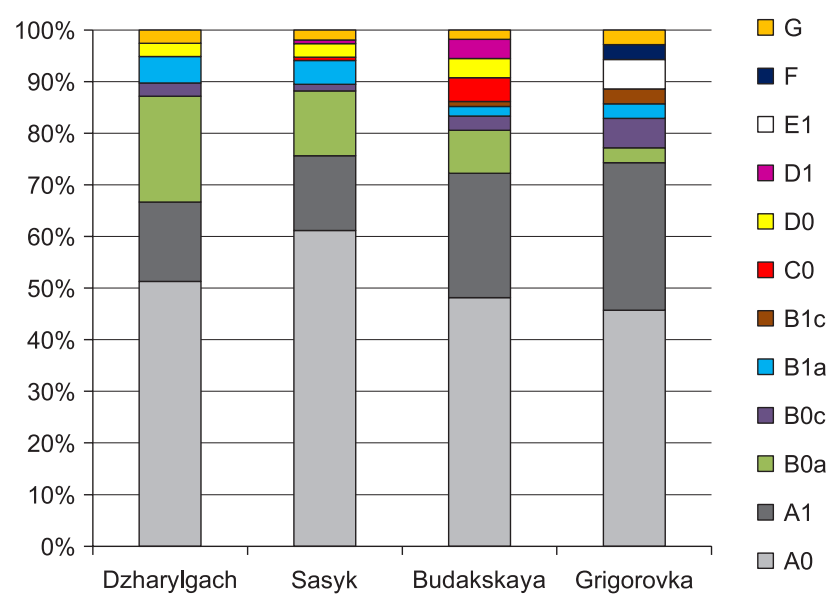

Fig. 4. Frequencies of shell patterns in four studied sites. For shell pattern codes see Figure 3



Fig. 5. Frequency of shell pattern colour in four studied sites

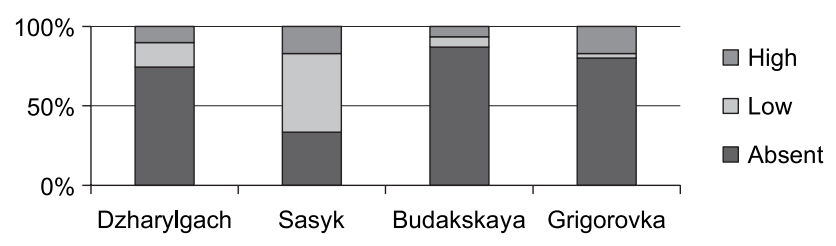

Fig. 6. Frequencies of classes of periostracum expression in four studied sites 
Table 5. Potential diversity of pattern elements, estimated by ACE with $95 \%$ confidence interval

\begin{tabular}{llrrr}
\hline \multicolumn{1}{c}{ ACE } & Pattern & $\begin{array}{c}\text { Shell } \\
\text { colour }\end{array}$ & $\begin{array}{r}\text { Pattern } \\
\text { colour }\end{array}$ \\
\hline Dzharylgach & Estimated & 11.094 & 5.701 & 8.570 \\
& Lower & 7.596 & 5.059 & 6.371 \\
& Upper & 35.098 & 13.286 & 35.803 \\
Sasyk & Estimated & 10.577 & 6.581 & 5.489 \\
& Lower & 9.194 & 6.045 & 5.035 \\
& Upper & 21.843 & 13.493 & 11.753 \\
Budakskaya & Estimated & 10.481 & 6.000 & 7.457 \\
& Lower & 10.041 & 6.000 & $\mathrm{~N} / \mathrm{A}$ \\
Grigorovka & Upper & 15.708 & 6.521 & $\mathrm{~N} / \mathrm{A}$ \\
& Estimated & 25.321 & 6.787 & 5.571 \\
& Lower & 12.288 & 5.193 & 5.053 \\
& Upper & 91.225 & 21.526 & 11.149 \\
\hline
\end{tabular}

Budakskaya populations was slightly higher than the total observed. The confidence intervals were wider in the Dzharylgach and Grigorovka populations due to the small number of individuals.

The main distinctive features of shells in the northern Black Sea are the prevalence of white, non-

\section{REFERENCES}

BĂCescu M. C., Dumitrescu E., Gomoiu M-T., Petran A. 1967. Elements pour la caracterisation de la zone sedimentaire medio-littorale de la mer Noire. Travaux du Muséum National d'Histoire Naturelle "Grigore Antipa" 7: 1-14.

CHAO A., LEE S. M. 1992. Estimating the number of classes via sample coverage. Journal of the American Statistical Association 87: 210-217. https://doi.org/10.1080/016 21459.1992.10475194

CHAO A., MA K. H., HSIEH T. C., CHIU C. H. 2016. User's guide for online program SpadeR (Species-richness prediction and diversity estimation in R). National Tsing Hua University, Taiwan.

Dumont H., MAmAeV V., ZAITSEV Y. 1999. Black Sea red data book. United Nations Office for Project Services.

Gaspar M. B., SANTOS M. N., VAsConcelos P., MONTEIRO C. C. 2002. Shell morphometric relationships of the most common bivalve species (Mollusca: Bivalvia) of the Algarve coast (southern Portugal). Hydrobiologia 477: 73-80.

HAMmer ̌̌., HaRper D. A. T., RYAN P. D. 2001. PAST: Paleontological Statistics Software Package for Education and Data Analysis. Palaeontologia Electronica 4: 1-9. http://palaeo-electronica.org/2001_1/past/issue1_01.htm

IBM CORP. 2017. IBM SPSS Statistics for Windows, Version 25.0. IBM Corp., Armonk, NY. streaked forms without radial pattern. The possible explanation is that the selective advantage of cryptic colouration is smaller on the northern Black Sea shores. However, a more detailed study is necessary to provide the reasons for these features.

The new records of $D$. cornea from the Ukrainian shores may help to specify localities of high conservation importance, which should be protected from direct anthropogenic pressure. The results of morphometric analyses may aid unambiguous species determination.

The study of northern Black Sea D. cornea revealed the need for investigations on its spatio-temporal structure. Though the depth segregation was indirectly confirmed for all the studied populations, the actual distribution of individuals remains unknown. Finding the factors which govern migration behaviour can aid development of monitoring strategy.

\section{ACKNOWLEDGEMENTS}

I am grateful to MiKhAIL SON and ALEXANDER KOSHELEV for collecting the samples.

KOPII V. G. 2012. Sovremennoe sostoyanie poselenij Donacilla cornea $\mathrm{v}$ pribrezhnih rajonah severo-zapadnoj chasti Chyornogo morya. Scientific Issue Ternopil Volodymyr Hnatiuk National Pedagogical University Series: Biology 51: 140-144.

MICU D., MICU S. 2006. Recent records growth and proposed IUCN status of Donacilla cornea (Poli, 1795) from the Romanian Black Sea. Cercetari Marine 36: 117-132.

SON M. O. 2014. About new records of rare species Donacilla (Mollusca, Bivalvia) and Ophelia bicornis in the Black Sea intertidal zone. Vestnik Zoologii 48: 189-190. https://doi.org/10.2478/vzoo-2014-0010

Whiteley D. A., OWEN D. F., SMITH D. A. 1997. Massive polymorphism and natural selection in Donacilla cornea (Poli, 1791) (Bivalvia: Mesodesmatidae). Biological Journal of the Linnean Society 62: 475-494. https://doi. org/10.1111/j.1095-8312.1997.tb00316.x

ZAKUTSKY V. P. 1967. Makrozoobentos. In: ZAKUTSKY V. P., VINOGRADOV K. A. (eds). Biologiya severo-zapadnoy chasti Chyornogo morya. Naukova dumka, Kiev, pp. 146-158.

Received: February 28th, 2020

Revised: June 6th/11th, 2020

Accepted: June 23rd, 2020

Published on-line: July 16th, 2020 